\title{
Calagem na nutrição de cálcio e no desenvolvimento do sistema radicular da goiabeira
}

\author{
Renato de Mello Prado(1) e William Natale ${ }^{(1)}$
} (1)Universidade Estadual Paulista, Fac. de Ciências Agrárias e Veterinárias, Dep. de Solos e Adubos, Via de Acesso Prof. Paulo Donato
Castellane, s/no, CEP 14870-000 Jaboticabal, SP. E-mail: rmprado@fcav.unesp.br, natale@fcav.unesp.br

\begin{abstract}
Resumo - A aplicação de calcário em solos ácidos promove maior desenvolvimento do sistema radicular das plantas e consequentemente, melhora a absorção de água e nutrientes. O objetivo deste trabalho foi avaliar os efeitos da aplicação de calcário no solo, no desenvolvimento do sistema radicular e na nutrição de cálcio de goiabeiras cultivadas em um Latossolo Vermelho distrófico ácido. Analisaram-se amostras de solo coletadas em quatro pontos equidistantes, a $75 \mathrm{~cm}$ do tronco, nas camadas de 0-20 e 20-40 $\mathrm{cm}$ de profundidade, de parcelas que receberam $0,3,7$ e 7,4 $\mathrm{t} \mathrm{ha}^{-1}$ de calcário. O calcário foi aplicado em pré-plantio, incorporado com arado de aivecas e grade aradora, na camada de $0-30 \mathrm{~cm}$ de profundidade. Durante o segundo e o terceiro ano de cultivo da goiabeira, avaliaram-se os efeitos da calagem nas propriedades químicas do solo. Aos 42 meses após a incorporação do calcário (terceiro ano de cultivo da goiabeira), realizou-se a amostragem das raízes com trado cilíndrico serrilhado para a avaliação da matéria seca e do teor de cálcio radicular e e também realizou-se a amostragem de folhas. A calagem promoveu a correção da acidez do solo, aumentando a saturação por bases, com conseqüente incremento da disponibilidade e absorção de cálcio pela planta, proporcionando maior desenvolvimento do sistema radicular da goiabeira. Concentrações de cálcio próximas de $30 \mathrm{mmol}_{\mathrm{c}} \mathrm{dm}^{-3}$ no solo e teor desse nutriente de 7,5 $\mathrm{g} \mathrm{kg}^{-1}$ nas raízes, estiveram associados ao maior crescimento radicular da goiabeira.
\end{abstract}

Termos para indexação: Psidium guajava, calcário, radicela, método do trado.

\section{Effect of the liming on the nutrition and the development of the guava root system}

\begin{abstract}
The application of lime in acid soils improves the plant root system and, consequently, enhances water and nutrients absorption by the plants. The objective of this work was to evaluate the effects of lime application on the development of root system and calcium nutrition of guava plants cultivated in an acid distrofic Red Latosol (Typic Hapludox). Soil samples were collected in four equidistant points, at $75 \mathrm{~cm}$ of the trunk and at 0-20 cm and 20-40 cm of depth, in the plots that had received zero (control), 3.7 and $7.4 \mathrm{tha}^{-1}$ of lime. Soil samples were chemically analysed. Lime material was applied at planting, incorporated with grating and moldboard plow. On the second and third years after guava plantation, effects of liming in chemical properties were determined. Forty two months after lime incorporation in the soil (third year of guava plants cultivation), samples of roots were collected with a cylindrical auger, for dry mass and calcium content evaluation. Samples of leaves were also collected. Liming corrected soil acidity increased base saturation and improved calcium availability to plants and, consequently, improved guava root system. Calcium concentrations of $30 \mathrm{mmol}_{\mathrm{c}} \mathrm{dm}^{-3}$ in the soil and of $7.5 \mathrm{~g} \mathrm{~kg} \mathrm{k}^{-1}$ in the roots were associated with the highest guava root growth.
\end{abstract}

Index terms: Psidium guajava, lime, radicel, auger method.

\section{Introdução}

A raiz é a parte da planta menos conhecida, menos pesquisada e compreendida, pelo fato de não poder ser vista facilmente e, ainda, pelas demais dificuldades impostas no seu estudo (Hughes et al., 1992). As pesquisas sobre o sistema radicular da goiabeira estão restritas aos aspectos básicos de distribuição espacial no solo, pois o sistema radicular dessa Myrtaceae estende-se horizontalmente, além da projeção da copa, atingindo mais de quatro metros de distância do caule, com maior concentração a $100 \mathrm{~cm}$, porém com escassos detalhes até essa distância (Moutounet et al., 1977). Trata-se de um sistema superficial de raízes, concentradas nas primeiras camadas do solo, de 0 a 30-40 cm (Purohit \& Mukherjee, 1974; Rey, 1998). Segundo Moutounet et al. (1977), cerca de 90\% das raízes finas (diâmetro <1 mm) da goiabeira 'Pink Indian' ocorrem nos primeiros $40 \mathrm{~cm}$ do solo e um terço exploram a camada mais superficial $(0-10 \mathrm{~cm})$. A intensidade da atividade radicular pode vari- 
ar horizontal e verticalmente com as estações do ano, com a disponibilidade de água e com o tipo de solo (Purohit \& Mukherjee, 1974; Kotur et al., 1998).

Além dos aspectos de distribuição do sistema radicular, o conhecimento de fatores que afetam o crescimento das raízes da planta é importante no manejo da goiabeira, quando se busca alta produtividade. Assim, Taylor \& Arkin (1981) relataram que o crescimento radicular das plantas, em geral, é controlado por fatores genéticos; entretanto, pode ser afetado por fatores físicos e químicos do solo. Segundo Miller (1986), as raízes estão sujeitas à falta ou excesso de água, deficiência de oxigênio, variação da temperatura, deficiência ou desequilíbrio de nutrientes, além de impedimentos físicos e presença de elementos tóxicos. Entre os fatores químicos, os mais estudados são os relacionados ao alumínio (Al) e ao cálcio (Ca). O Al tóxico reduz o crescimento radicular (Adams \& Pearson, 1970; Pavan et al., 1982), especialmente o ápice das raízes (Kochian, 1995). O Ca, por sua vez, é um nutriente com papel preponderante no crescimento radicular das plantas (Ritchey et al., 1982). Quando a saturação de Ca no complexo de troca é inferior a $20 \%$, há forte limitação ao crescimento das raízes no solo, na maioria das espécies cultivadas (Quaggio, 2000). Segundo o autor, a absorção de Ca ocorre apenas nas partes mais novas, ainda não suberizadas das raízes, havendo assim necessidade de absorção contínua desse nutriente para assegurar o desenvolvimento do sistema radicular, o que implica que o Ca deve estar distribuído adequadamente no solo. É importante acrescentar que estes fatores químicos que afetam o crescimento radicular são muito importantes nas áreas tropicais, tendo em vista que grande parte dos solos desta região apresenta reação ácida, com alta concentração de $\mathrm{Al}$ tóxico e baixo conteúdo de cálcio. Além disso, sucessivas aplicações de fertilizantes de reação ácida, como os adubos nitrogenados, causam forte acidificação dos solos de pomares de fruteiras, especialmente na projeção da copa. De acordo com Foy (1984), a toxicidade de alumínio é o principal fator limitante ao estabelecimento de diferentes culturas em solos ácidos. Portanto, a presença de Ca na solução do solo, em contato com o sis- tema radicular é essencial à sobrevivência das plantas, pois esse nutriente não se transloca da parte aérea para as porções novas das raízes em crescimento (Caires et al., 2001).

O objetivo deste trabalho foi avaliar os efeitos da aplicação de calcário no solo, no desenvolvimento do sistema radicular e na nutrição de cálcio de goiabeiras cultivadas em Latossolo Vermelho distrófico ácido.

\section{Material e Métodos}

O experimento foi realizado na Estação Experimental de Citricultura de Bebedouro, situada à rodovia Brigadeiro Faria Lima (SP 326), Km 384, a 5 km do Município de Bebedouro, SP (latitude: 2053'16"S; longitude: 48²8'11"W; altitude: $601 \mathrm{~m})$. Segundo a classificação de Köppen, o clima local é do tipo Cwa subtropical com inverno curto, moderado e seco, e verão quente e chuvoso, caracterizando duas estações distintas. O solo é um Latossolo Vermelho distrófico ácido e antes da implantação do ensaio foram coletadas 20 subamostras para compor uma amostra composta nas camadas de 0-20, 20-40 e 40-60 cm. Os resultados das análises químicas dessas amostras encontram-se na Tabela 1.

Em agosto de 1999, aplicou-se calcário magnesiano, objetivando elevar em uma e duas vezes a saturação por bases igual a $70 \%$. O calcário utilizado possuía $456 \mathrm{~g}$ de $\mathrm{CaO} \mathrm{kg}{ }^{-1}, 102 \mathrm{~g} \mathrm{de} \mathrm{MgO} \mathrm{kg}^{-1}, \mathrm{RE}=94 \%, \mathrm{PN}=107 \%$ e PRNT $=100 \%$.

A saturação por bases igual a $70 \%$ foi indicada como ideal para a cultura da goiaba, de acordo com Santos \& Quaggio (1996). O calcário foi aplicado manualmente em toda a superfície do terreno, metade antes da incorporação com arado de aivecas e, outra metade, aplicada e incorporada com grade aradora. A incorporação do corretivo foi realizada até a profundidade de $30 \mathrm{~cm}$.

Seis meses após o pegamento das mudas, instalou-se o sistema de irrigação por microaspersão colocando-se um microaspersor por planta, com vazão de $26 \mathrm{~L} \mathrm{~h}^{-1}$, raio de $1 \mathrm{~m}$ e turno de rega de 3,5 dias com duração de 4-5 horas. O sistema de irrigação foi acionado sempre que a umidade do solo foi considerada baixa.

Tabela 1. Propriedades químicas do solo da área experimental antes da calagem.

\begin{tabular}{cccccccrrr}
\hline $\begin{array}{c}\text { Profundidade } \\
(\mathrm{cm})\end{array}$ & $\mathrm{pH}\left(\mathrm{CaCl}_{2}\right)$ & $\begin{array}{c}\mathrm{MO} \\
\left(\mathrm{g} \mathrm{dm}^{-3}\right)\end{array}$ & $\begin{array}{c}\mathrm{P}(\mathrm{resina}) \\
\left(\mathrm{mg} \mathrm{dm}^{-3}\right)\end{array}$ & $\mathrm{K}$ & $\mathrm{Ca}$ & $\mathrm{Mg}$ & $\begin{array}{c}(\mathrm{H}+\mathrm{Al}) \\
\mathrm{SB}\end{array}$ & $\begin{array}{c}\mathrm{T} \\
(\%)\end{array}$ \\
\hline $0-20$ & 4,7 & 18 & 6 & 1,3 & 9 & 4 & 40 & 14,3 & 54,3 \\
$20-40$ & 4,4 & 16 & 3 & 0,6 & 6 & 3 & 42 & 9,6 & 51,6 \\
$40-60$ & 4,4 & 16 & 4 & 0,6 & 7 & 4 & 45 & 11,6 & 56,6 \\
\hline
\end{tabular}

Pesq. agropec. bras., Brasília, v.39, n.10, p.1007-1012, out. 2004 
A precipitação média anual em 2000, 2001 e 2002 foi de $1.636,1.153$ e $1.421 \mathrm{~mm}$, respectivamente.

Considerando que o desenvolvimento do sistema radicular é consequiência das condições do ambiente químico do solo, utilizaram-se as médias dos parâmetros avaliados nas amostragens de solo da linha de plantio da fruteira, na faixa de adubação, realizadas aos 12, 16, 22, 28, 34 e 40 meses após a incorporação do calcário. Empregou-se trado tipo holandês, coletando-se amostras nas camadas de 0-20, 20-30 e 30-40 cm de profundidade. Aos 42 meses após a incorporação do calcário, realizou-se a amostragem das raízes, empregando-se trado cilíndrico serrilhado, com 7,4 cm de diâmetro interno e $20 \mathrm{~cm}$ de altura (Fujiwara et al., 1994). Em seguida, as amostras para avaliação radicular foram acondicionadas em sacos de plástico e levadas ao laboratório, onde foram passadas em peneiras com $1 \mathrm{~mm}$ de malha. As raízes foram lavadas e secadas em estufa a $70^{\circ} \mathrm{C}$ até massa constante, para a obtenção da massa radicular.

O delineamento experimental adotado foi em blocos casualizados com três doses de calcário e quatro repetições. As parcelas eram compostas por cinco goiabeiras (cv. Paluma), propagadas a partir de estacas herbáceas. Na época da amostragem das raízes, as plantas estavam com cerca de três anos de idade, espaçadas de 7,0x4,2 m, sendo consideradas as três centrais como árvores úteis nas avaliações. Em cada uma das plantas úteis, coletou-se amostras de raízes em quatro pontos eqüidistantes, a $75 \mathrm{~cm}$ do tronco, perfazendo 12 repetições em cada profundidade (0-20 e 20-40 cm). Optouse pelo maior número de repetições, tendo em vista a alta variabilidade dos dados em estudos de raiz, aumentando a possibilidade de detecção dos efeitos dos tratamentos.

Determinou-se o teor foliar de Ca no 3o par de folhas recém-maduras, com pecíolo, em pleno florescimento, conforme Natale et al. (1996). A determinação dos teores de $\mathrm{Ca}$ nas folhas e nas raízes foi feita conforme Bataglia et al. (1983). As análises químicas das amostras de solo foram realizadas conforme Raij et al. (2001).

Os resultados foram submetidos à análise de variância e regressão, e analisados segundo as equações com o melhor ajuste, confirmadas pelo maior valor do coeficiente de determinação.

\section{Resultados e Discussão}

A aplicação de calcário aumentou o pH, as concentrações de $\mathrm{Ca}$ e o índice de saturação por bases nas diferentes amostragens realizadas na linha da goiabeira
(Figura 1). A calagem promoveu melhoria da reação do solo e aumento do $\mathrm{Ca}$ até $40 \mathrm{~cm}$ de profundidade, indi-
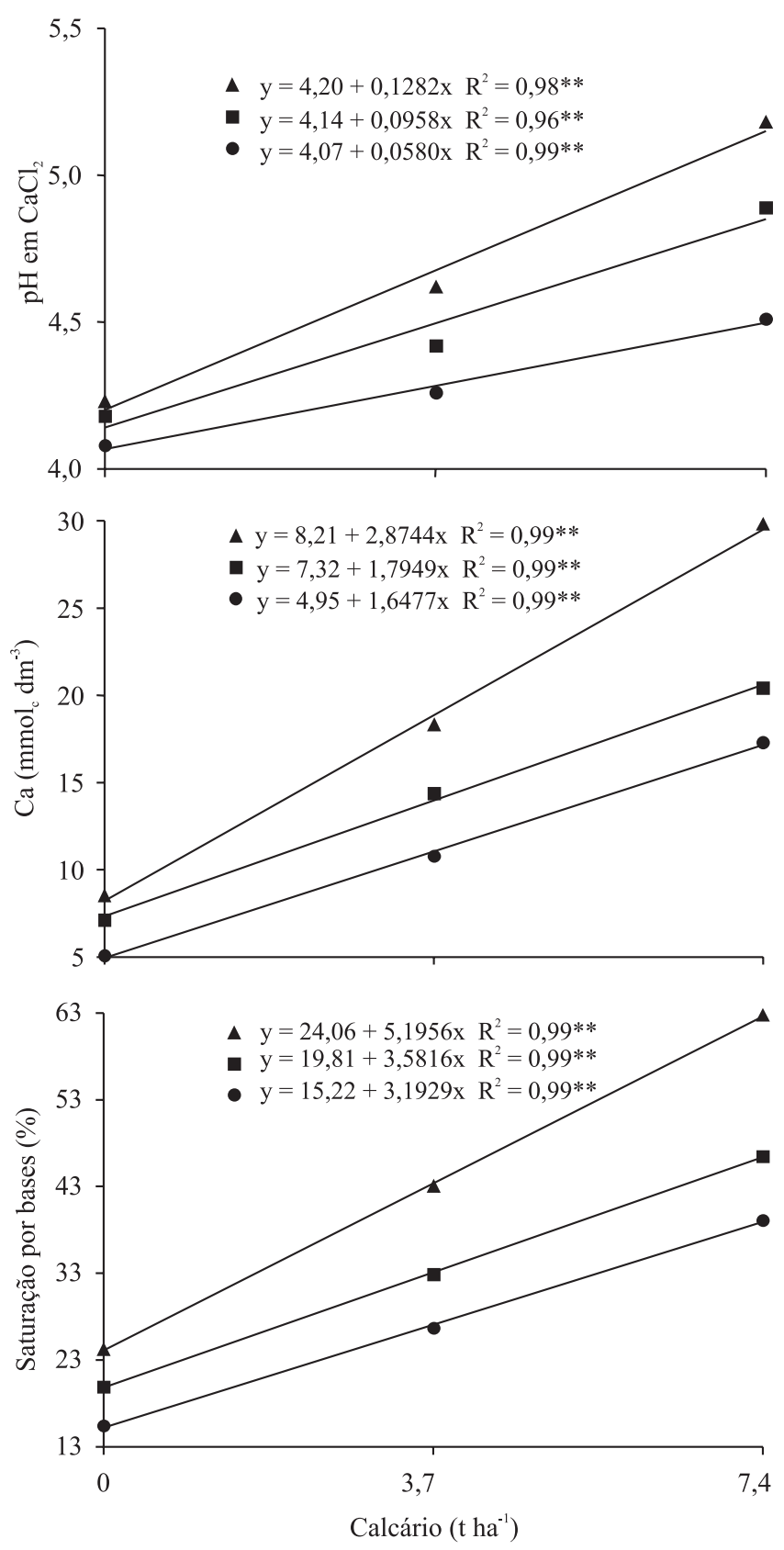

Figura 1. Efeito da aplicação de calcário sobre o pH, concentração de cálcio e saturação por bases, em diferentes profundidades do solo, em amostras da linha da goiabeira. Os pontos são médias de oito, seis e cinco épocas de amostragem para

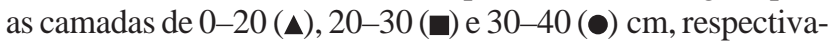
mente, e quatro repetições. **Significativo a $1 \%$ de probabilidade pelo teste $\mathrm{F}$. 
cando movimento deste elemento no perfil do solo. Esse movimento, segundo Aoyama (1996), se deve à formação de pares entre o Ca e ácidos orgânicos do solo ( $\mathrm{RO}^{-}$ e $\mathrm{RCOO}^{-}$), formando um composto móvel no solo.

$\mathrm{O}$ aumento da concentração de $\mathrm{Ca}$ no solo teve reflexos no teor foliar, atingindo $13 \mathrm{~g} \mathrm{~kg}^{-1}$ no terceiro ano de cultivo da goiabeira (Figura 2). De acordo com Natale et al. (1996), os teores de Ca nas folhas estão acima daqueles considerados adequados para a goiabeira ( 7 a $\left.11 \mathrm{~g} \mathrm{~kg}^{-1}\right)$.

A aplicação de calcário aumentou, de forma linear, a massa radicular da goiabeira (a $75 \mathrm{~cm}$ do tronco), tanto na camada de $0-20 \mathrm{~cm}$ como na de $20-40 \mathrm{~cm}$ de profundidade (Figura 3). Isto pode ser explicado pelo aumento do teor de Ca no solo, o que causou maior absorção desse nutriente pelas raízes, refletindo no acúmulo de matéria seca radicular (Figura 4).

A resposta linear da goiabeira no crescimento radicular, mesmo na maior dose de calcário (Figura 3), demonstra que não houve restrição ao desenvolvimento desse órgão, indicando que as raízes dessa fruteira são altamente responsivas ao $\mathrm{Ca}$ (Figura 4).

$\mathrm{O}$ efeito benéfico da calagem sobre o sistema radicular pode ser explicado pela relação positiva entre o $\mathrm{Ca}$ do solo e a massa radicular da goiabeira, que resultou em uma maior absorção de Ca pelas raízes (Figura 5). O teor de Ca no solo que promoveu maior crescimento radicular foi de $29,28 \mathrm{mmol}_{\mathrm{c}} \mathrm{dm}^{-3}$. A relação entre o teor de $\mathrm{Ca}$ no solo e nas raízes foi quadrática (Figura 5) e o teor de

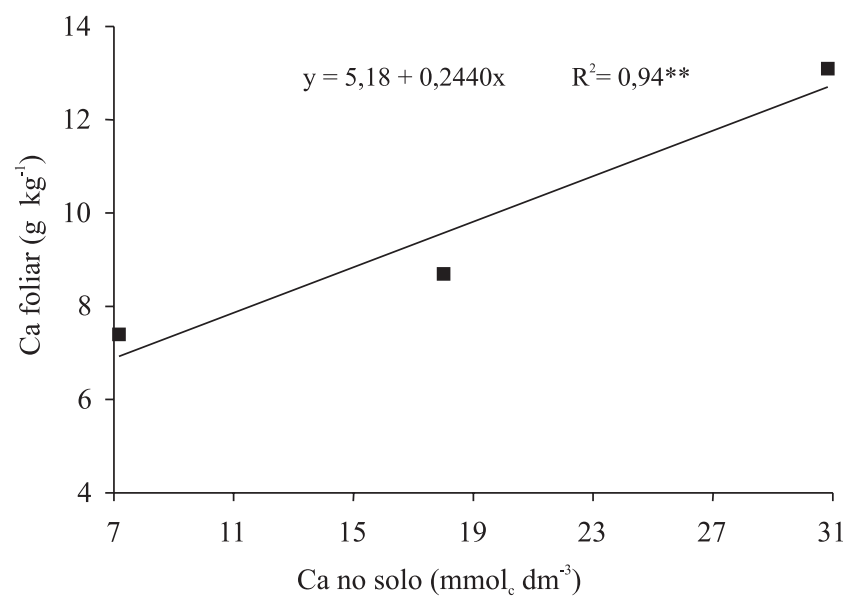

Figura 2. Relação entre as concentrações de cálcio no solo (camada de 0-20 cm de profundidade) e nas folhas da goiabeira no terceiro ano de cultivo, em função da aplicação do calcário. **Significativo a $1 \%$ de probabilidade pelo teste $\mathrm{t}$.
Ca no solo, que maximizou o teor de Ca nas raízes, foi $27,69 \mathrm{mmol}_{\mathrm{c}} \mathrm{dm}^{-3}$, o que corresponde a $7,47 \mathrm{~g} \mathrm{~kg}^{-1} \mathrm{de}$ $\mathrm{Ca}$ nas raízes. A relação entre o $\mathrm{Ca}$ no solo e o Ca na folha foi linear (Figura 2). Porém, substituindo-se o teor de Ca no solo que maximizou o teor de Ca nas raízes na equação ajustada, obteve-se $11,93 \mathrm{~g} \mathrm{~kg}^{-1}$ de Ca na folha da goiabeira. Prado et al. (2002) observaram 7,0 $\mathrm{g} \mathrm{kg}^{-1}$ de Ca na parte aérea e 4,5 $\mathrm{g} \mathrm{kg}^{-1}$ de Ca nas raízes. Prado (2003) observou que concentração de Ca próxima

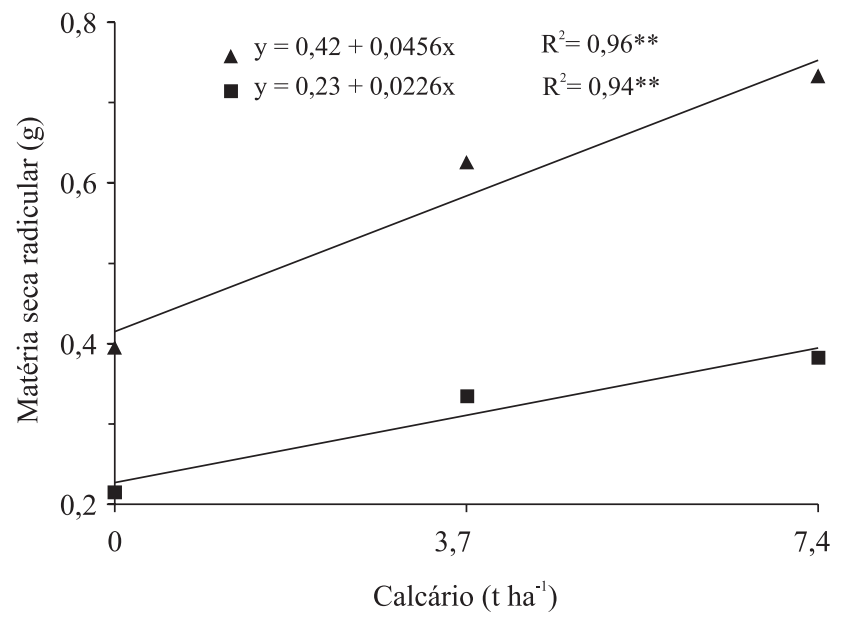

Figura 3. Efeito da aplicação de calcário sobre a matéria seca radicular da goiabeira, determinada nas camadas de 0-20 (A) e 20-40 (ם) cm de profundidade, a $75 \mathrm{~cm}$ do tronco. Médias de 12 repetições. $* *$ Significativo a $1 \%$ de probabilidade, pelo teste $\mathrm{t}$.

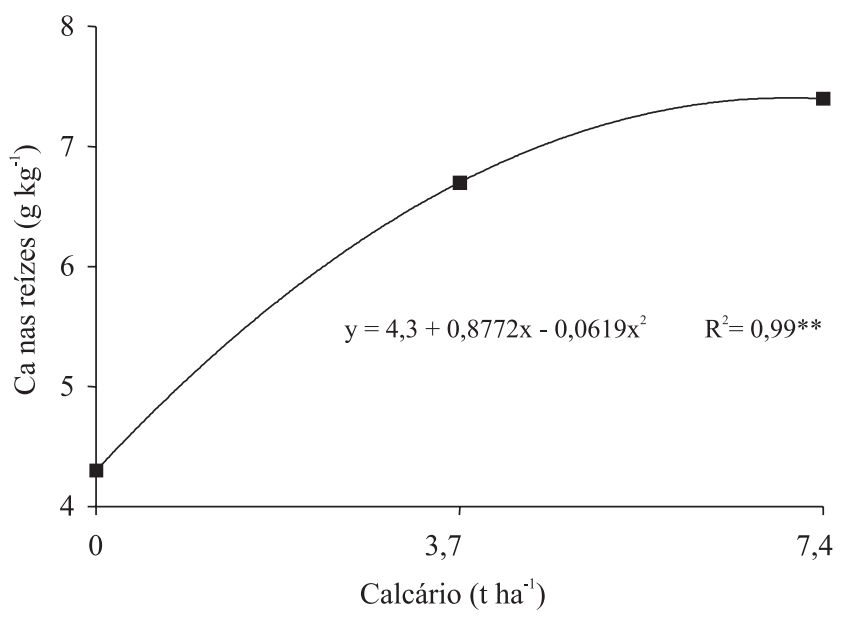

Figura 4. Efeito da aplicação de calcário sobre o teor de cálcio de raízes da goiabeira, na camada de $0-20 \mathrm{~cm}$ de profundidade, a $75 \mathrm{~cm}$ do tronco. Médias de 12 repetições. **Significativo a $1 \%$ de probabilidade pelo teste $\mathrm{t}$. 
de 29,28 $\mathrm{mmol}_{\mathrm{C}} \mathrm{dm}^{-3}$ no solo resultou em maior produção de frutos da goiabeira.
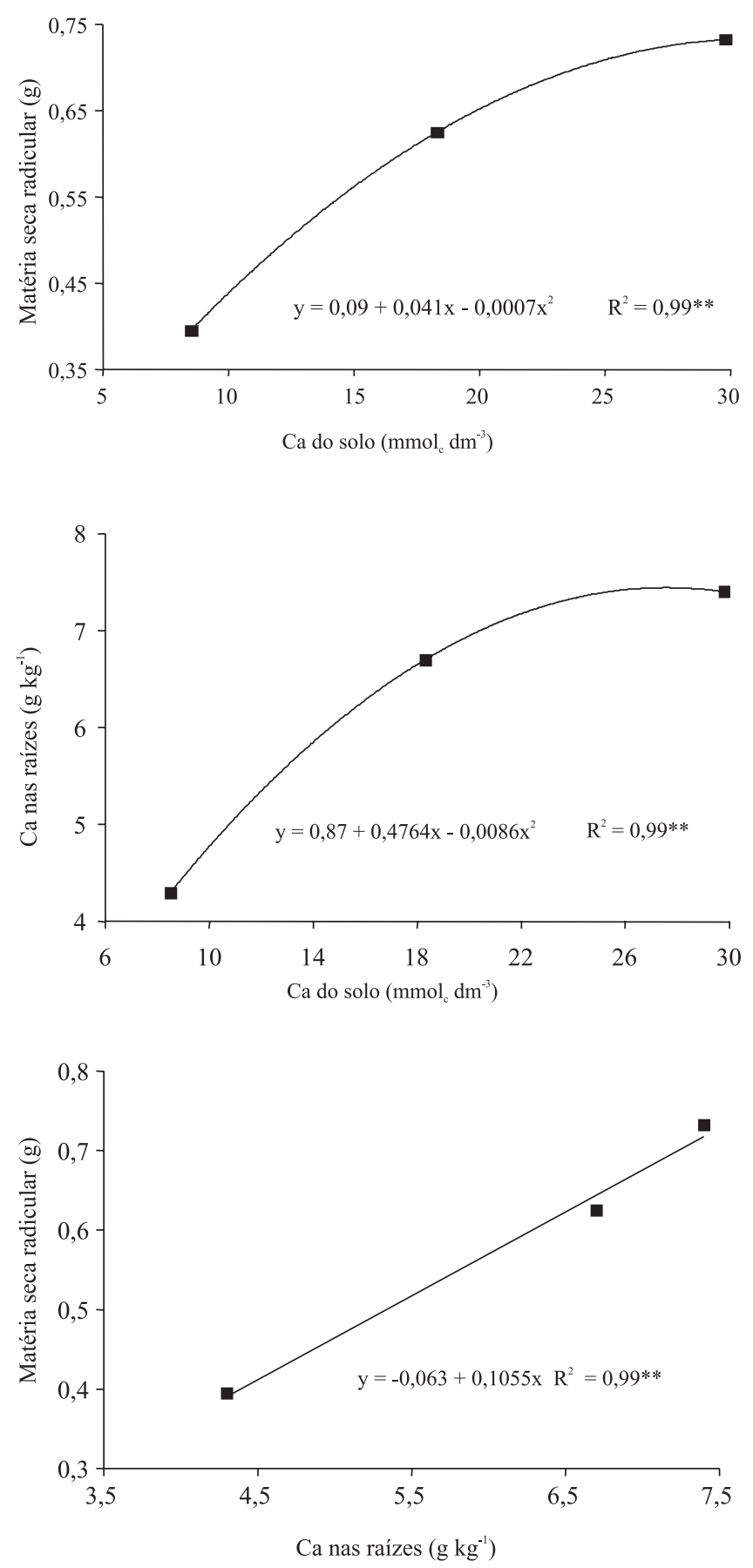

Figura 5. Efeito do cálcio do solo sobre a matéria seca radicular da goiabeira na camada de $0-20 \mathrm{~cm}$ de profundidade, a $75 \mathrm{~cm}$ do tronco; relação entre o cálcio do solo e o teor de cálcio nas raízes; e relação entre o teor de Ca nas raízes e a matéria seca radicular. Médias de 12 repetições. ${ }^{* *}$ Significativo a $1 \%$ de probabilidade pelo teste $\mathrm{F}$.
A relação linear entre o teor de $\mathrm{Ca}$ nas raízes e a massa radicular (Figura 5), revela o efeito benéfico do Ca no desenvolvimento radicular das plantas (Ritchey et al., 1982). A importância do Ca para as plantas devese ao fato de que cerca de $60 \%$ do Ca celular está presente na parede celular (Tobias et al., 1993). Assim, a principal função desse nutriente é estrutural, como integrante da parede celular. Normalmente, quando as células crescem, aumenta a superfície de contato entre elas, aumentando também a necessidade do suprimento de $\mathrm{Ca}$ (pectato de cálcio) para a formação da pectina, conferindo a elongação da parede celular até atingir o tamanho final.

A concentração de Ca no solo $\left(2,5-8,0 \mathrm{mmol}_{\mathrm{c}} \mathrm{dm}^{-3}\right)$ tem sido indicada como valor crítico para o maior crescimento radicular (Adams \& Moore, 1983). No caso da goiabeira, o valor de Ca no solo foi ainda maior, cerca de $30 \mathrm{mmol}_{\mathrm{c}} \mathrm{dm}^{-3}$. Portanto, a determinação da concentração de Ca no solo poderia ser indicativa para diagnóstico do potencial de crescimento radicular dessa fruteira. As variações nas respostas entre diferentes espécies de plantas ocorrem por causa de fatores genéticos ligados à eficiência dos vegetais na utilização desse nutriente (Clark, 1976 citado por Raij, 1988). Além disso, a goiabeira é uma dicotiledônea e, segundo Melo et al. (1987), este grupo de plantas apresenta raízes com alta CTC, ou seja, alta capacidade de absorver cátions divalentes. No caso da goiabeira, espera-se que a exigência da planta na fase de formação seja maior que na de produção, uma vez que nos primeiros anos de implantação do pomar ocorre formação da estrutura da planta, e o Ca é requerido em maior quantidade. Após a formação, a exigência da planta diminui, tendo em vista que a extração de $\mathrm{Ca}$ pelos frutos é relativamente baixa. Dentre os macronutrientes, o Ca foi o menos exportado pelos frutos da goiabeira 'Paluma', cerca de $94 \mathrm{~g}$ por tonelada de fruta fresca (Natale et al.,1994).

\section{Conclusões}

1. A calagem aumenta a disponibilidade e absorção de Ca pela planta, proporcionando maior desenvolvimento do sistema radicular da goiabeira.

2. Concentrações de Ca próximas de $30 \mathrm{mmol}_{\mathrm{c}} \mathrm{dm}^{-3}$ no solo e de 7,5 $\mathrm{g} \mathrm{kg}^{-1}$ nas raízes estiveram associadas ao maior crescimento radicular da goiabeira.

\section{Agradecimentos}

À FAPESP, pelo auxílio financeiro.

Pesq. agropec. bras., Brasília, v.39, n.10, p.1007-1012, out. 2004 


\section{Referências}

ADAMS, F.; MOORE, B.L. Chemical factors affecting root growth in subsoil horizons of coastal plain soils. Soil Science Society of American Journal, v.47, p.99-102, 1983.

ADAMS, F.; PEARSON, R.W. Differencial response of cotton and peanuts to subsoil acidity. Agronomy Journal, v.62, p.9-12, 1970.

AOYAMA, M. Fractionation of water-soluble organic substances formed during plant residue decomposition and high performance size exclusion chromatography of the fractions. Soil Science and Plant Nutrition, v.42, p.31-40, 1996.

BATAGLIA, O.C.; FURLANI, A.M.C.; TEIXEIRA, J.P.F.; FURLANI, P.R.; GALLO, J.R. Métodos de análise química de plantas. Campinas: Instituro Agronômico, 1983. 48p. (Boletim Técnico, 78)

CAIRES, E.F.; FONSECA, A.F.; FELDHAUS, I.C.; BLUM, J. Crescimento radicular e nutrição da soja cultivada no sistema plantio direto em resposta ao calcário e gesso na superfície. Revista Brasileira de Ciência do Solo, v.25, p.1029-1040, 2001.

FOY, C.D. Physiological effects of hydrogen, aluminum and manganese toxicities in acid soil. In: ADAMS, F. (Ed.). Soil acidity and liming. Madison: American Society of Agronomy, 1984 p. 5797.

FUJIWARA, M.; KURACHI, S.A.H.; ARRUDA, F.B.; PIRES, R.C.M.; SAKAI, E. A técnica de estudo de raízes pelo método do trado. Campinas: Instituto Agronômico, 1994. 9p. (Boletim Técnico, 153).

HUGHES, K.A.; HORNE, D.J.; ROSS, C.W.; JULIAN, J.F. A 10-year maize/oats rotation under three tillage systems: 2 . Plant population, root distribution and forage yields. Soil and Tillage Research, v.22, p.145-157, 1992.

KOCHIAN, L.V. Cellular mechanisms of aluminum toxicity and resistance in plants. Annual Review of Plant Physiology and Plant Molecular Biology, v.46, p.237-260, 1995.

KOTUR, S.C.; KESHAVA MURTHY, S.V.; IYENGAR, B.R. Spatial distribution of active roots in 'Arka Mridula' guava (Psidium guajava) as influenced by seasons, soil-moisture and growth. Indian Journal of Agricultural Science, v.68, p.744-746, 1998.

MELO, F.A.F.; BRASIL SOBRINHO, M.O.C.; ARZOLLA, S.; SILVEIRA, R.I.; NETTO, A.C.; KIEHL, J.C. Fertilidade do solo. 3. ed. São Paulo: Nobel, 1987. p.265-335.

MILLER, D.E. Root systems in relation to stress tolerance. HortScience, v.21, p.963-970,1986.

MOUTOUNET, B.; AUBERT, B.; GOUSSELAND, J.; TIAWCHAN, P. Etude de l'enracinement de quelques arbres fruitiers sur sol ferrallitique brun profond. Fruits, v.32, p.321-333, 1977.
NATALE, W.; COUTINHO, E.L.M.; BOARETTO, A.E.; PEREIRA, F.M. Goiabeira: calagem e adubação. Jaboticabal: Funep, 1996. 22p.

NATALE, W.; COUTINHO, E.L.M.; BOARETTO, A.E.; COSTEZ, G.E.P.; FESTUCCIA, A.J. Extração de nutrientes por frutos de goiabeira (Psidium guajava L.). Revista Científica, v.22, p.249-253, 1994.

PAVAN, M.A.; BINGHAM, F.T.; PRATT, P.F. Toxicity of aluminium to coffee in Ultisols and Oxisols amended with $\mathrm{CaCO}_{3}$, $\mathrm{MgCO}_{3}$ and $\mathrm{CaSO}_{4}$. Soil Science Society of America Journal, v.46, p.1201-1207, 1982.

PRADO, R. de M. Efeitos da calagem no desenvolvimento, no estado nutricional e na produção de frutos da goiabeira e da caramboleira. 2003. 68p. Tese (Doutorado) - Universidade Estadual Paulista, Jaboticabal.

PRADO, R.M.; CORRÊA, M.C.M.; NATALE, W. Efeito da cinza da indústria de cerâmica no solo e na nutrição de mudas de goiabeira. Acta Scientiarum, v.24, p.1493-1500, 2002.

PUROHIT, A.G.; MUKHERJEE, S.K. Characterizing root activity of guava trees by radiotracer technique. Indian Journal of Agricultural Sciences, v.44, p.575-581, 1974.

QUAGGIO, J.A. Acidez e calagem em solos tropicais. Campinas: Instituto Agronômico, 2000. 111p.

RAIJ, B. van. Gesso agrícola na melhoria do ambiente radicular no subsolo. São Paulo: Associação Nacional para Difusão de Adubos e Corretivos Agrícolas, 1988. 88p.

RAIJ, B. van; ANDRADE, J.C.; CANTARELLA, H.; QUAGGIO, J.A. (Ed.) Análise química para avaliação da fertilidade do solo. Campinas: Instituto Agronômico, 2001. 285p.

REY, J.Y. L'étude architecturale du goyavier. II expérimentations. Fruits, v.53, p.241-255, 1998.

RITCHEY, K.D.; SILVA, J.E.; COSTA, U.F. Calcium deficiency in clayey B horizons of savanna oxisols. Soil Science, v.133, p.378382, 1982.

SANTOS, R.R.; QUAGGIO, J.A. Goiaba. In: RAIJ, B. van; CANTARELLA, H.; QUAGGIO, J.A.; FURLANI, A.M.C. (Ed.). Recomendações de adubação e calagem para o Estado de São Paulo. Campinas: Instituto Agronômico, 1996. p.143. (Boletim Técnico, 100)

TAYLOR, D.; ARKIN, G.F. Root zone modification fundamentals alternatives. In: TAYLOR, H.M.; ARKIN, G.F. (Ed.). Modifying the root environment to reduce crop stress. St. Joseph: ASAE, 1981. p.3-16.

TOBIAS, R.B.; CONWAY, W.S.; SAMS, C.E.; GROSS, K.C.; WHITAKER, B.D. Cell wall composition of calcium-treated apples inoculated with Botrytis cinerea. Phytochemistry, v.32, p.35-39, 1993.

$\overline{\text { Recebido em } 23 \text { de abril de } 2004 \text { e aprovado em } 6 \text { de julho de } 2004}$ 